UDC 316.353

LBC 60.54

\title{
DYNAMICS OF YOUTH VALUES IN THE SAMARA REGION
}

\author{
Vladimir B. Zvonovsky \\ Samara State University of Economics, Samara, Russian Federation
}

\begin{abstract}
The article discusses the dynamics of changes in the value orientations of the age group of young people in the 10s of the 21 st century compared with the values of the similar group of the "zero" years of the 21 st century, as well as the transformation of the hierarchy of the problems the youth group deal with as the challenges facing young people preferences and their changes in the last 15 years. Researchers identify two periods of transformation of Russian youth values. The first one can be limited to the period between 1995 and 2005. It was caused by the breaking of the main part of social institutions, where the processes of youth socialization took place. The present youth group, which entered this period after 2008, passed the final phase of socialization after the formation of the modern Russian economic system that had defined the structure of employment and work ethics. By this time, the period of uncertainty and the feelings of instability and pessimism, stimulating the consolidation of asocial attitudes, had already ended.

In this regard, sociologists of the Social Research Fund repeated the previous stages of their monitoring of young people in the Samara region, which took place from 1993 to 2004. The article mainly presents the results of the measurement carried out in the summer of 2018, i.e. 15 years after the previous measurement. During this period, the age cohort, which related to young people in the previous waves of research, has been updated almost completely. The results of the study show a significant weakening of interest in education, especially higher education, consistently high focus on life success and career and the continuing peripherality of political activity for young people. In particular, it is shown that the hierarchy of values has acquired qualitatively new features that are not typical of the former youth groups and the behavior of older age groups.
\end{abstract}

Key words: youth, values, dynamics, education, career, Samara.

УДК 316.353

ББК 60.54

\section{ДИНАМИКА ЦЕННОСТЕЙ МОЛОДЕЖИ САМАРСКОЙ ОБЛАСТИ}

\author{
Владимир Борисович Звоновский \\ Самарский государственный экономический университет, г. Самара, Российская Федерация
}

Аннотация. В статье обсуждается динамика изменений ценностных ориентаций возрастной группы молодежи 10-х гг. XXI в. по сравнению с ценностями аналогичной группы «нулевых» годов XXI в., а также трансформация иерархии проблем, с которыми сталкиваются молодые люди, таких как вызовы, стоящие перед ними при реализации ценностных предпочтений и их изменении в последние 15 лет. Исследователи выделяют два периода трансформации ценностных ориентаций российской молодежи. Первый можно ограничить диапазоном между 1995 и 2005 годами. Он был вызван сломом основной части социальных институтов, в рамках которых происходили процессы социализации молодежи. Нынешняя молодежная группа относится ко второму периоду - после 2008 г. - и проходит финальную фазу социализации уже после окончания формирования современной российской экономической системы и определяемой ею структуры занятости и трудовой этики. К этому времени уже закончилось время неопределенности и исчезли связанные с ним ощущения нестабильности и пессимизма, стимулирующие закрепление асоциальных установок.

В связи с этим социологи Фонда социальных исследований повторили предыдущие этапы своего мониторинга молодежи Самарской области, проходившего с 1993 по 2004 год. В статье представлены в основном итоги анализа, проведенного летом 2018 г., то есть спустя 15 лет после предыдущего. За этот период возрастная когорта, которая в предыдущих волнах исследования относилась к молодежи, обновилась почти 
полностью. Результаты исследования показывают существенное ослабление интереса к образованию, особенно высшему, устойчиво высокую нацеленность на жизненный успех и карьеру и сохраняющуюся периферийность политической деятельности для молодежи. В частности, показано, что иерархия ценностей молодых людей приобрела качественно новые черты, не свойственные прежним молодежным группам и поведению старших возрастных групп.

Ключевые слова: молодежь, ценности, динамика, образование, карьера, Самара.

Традиционно внимание социологов обращено к изучению ценностных ориентаций современной молодежи, чему посвящено множество социологических работ [2, с. 66-77; 3 , с. 99-118; 6; 7; 9] Система ценностных ориентаций определяет содержательное наполнение личности, ее отношение к явлениям, другим людям, к себе самой составляет основу мировоззрения и жизненную концепцию. Но важна не только ценностная система человека, определяющая его отношение к миру, но и то, насколько очевидна эта система каждой отдельной личности, вступающей в социальное взаимодействие. Так, люди рассчитывают на то, что их визави (очные или заочные, персональные или массовые) разделяют примерно те же самые ценности и идеалы. Или, напротив, знают, а порой даже акцентируют отличия своих ценностных представлений от представлений других социальных групп. Очевидно, что молодежь имеет иные ценности и потребности, в отличие от старших поколений. В связи с этим изучение ценностей является важной социологической задачей, так как ценности, которыми руководствуются молодые люди сегодня, будут определять следующий этап развития общества.

Практически все посвященные данной тематике исследования, проведенные в 90-х гг. прошлого века и первом десятилетии 2000-х гг., касаются трансформации ценностных ориентаций в период становления рыночной экономики. Последний характеризуется изменением базовых принципов жизнедеятельности всего общества, «ломкой ценностей», переосмыслением норм, позиций, стратегий поведений [10, с. 45-48; 1, с. 76-96]. Молодежь, как наиболее восприимчивая и приспосабливающаяся к новым условиям часть общества, с легкостью усваивает новые правила, ценности и адаптируется к новым условиям. Так, например, исследование трансформации жизненных ценностей россиян в период модернизации показало становление ценностей рыночного об- щества, которые нашли наибольшую поддержку у молодежи [7]. Новые социально-экономические условия определили развитие таких ценностей молодых людей, как инициативность, предприимчивость, стремление рисковать и др., то есть характеристики «делового» человека [1, с. 45-57; 3, с. 99-118]. Новые ценностные ориентации и притязания нашли свое отражение, прежде всего, в изменении способов достижения целей, улучшении материального положения, освоении новых трудовых практик и т. п.

Однако после 2005-2010 гг. исследования ценностных ориентаций российской молодежи встречаются крайне редко. Некоторым исключением являются работы, касающиеся изучения протестного движения, а также добровольчества в России, значительную роль в которых сыграла и играет молодежь $[1$, c. 25-27; 8]. Уже они показали совершенно новые явления в молодежной среде, которых не было 10 или 20 лет назад. Лишь недавно стали появляться работы, в центре которых находится молодежь как самостоятельный объект изучения [13, с. 15-33; 4, с. 42-53]. Уже в них авторы указывают на возникновение новых ценностных ориентаций нынешней молодежи, нехарактерных для молодежи 90-х годов. Именно на этих отличиях мы сосредоточили исследовательский поиск, используя возможность сопоставления опросных данных, зафиксировавших мнение и поведение молодежи предыдущих периодов с данными, собираемыми сегодня.

На процесс формирования ценностных ориентаций воздействуют различные факторы: семья, сверстники, образовательные учреждения, общественное мнение и т. п. Ценностные ориентации молодежи меняются с каждым поколением, поскольку, во-первых, происходит смена экономических, социальных и политических условий ее социализации, а вовторых, каждое поколение формирует собственную ценностную подсистему, акцентиру- 
ющую отличия в стандартах поведения и стереотипах общественного мнения от других возрастных групп. Отчасти смена ценностных ориентиров происходит по мере обновления самой молодежной страты, отчасти под влиянием изменений социальных условий жизни группы.

Исследователи выделяют два периода трансформации ценностных ориентаций российской молодежи. Первый можно ограничить диапазоном между 1995 и 2005 годами. Он был вызван сломом основной части социальных институтов, в рамках которых происходили процессы социализации молодежи. В частности, в советский период государственная монополия на хозяйственную деятельность, однозначно определяла воспроизводство социальных групп, внутри которых происходила социализация молодежи. Последовавшее затем разрушение традиционных каналов успешной социализации молодежи, а также включение ее в трудовые практики способствовали развитию инновационного потенциала, использованию нестандартных методов приспособления молодежи к сложившимся условиям. Произошедшие изменения радикально повлияли на институт семьи. Новые поколения россиян, получившие навыки жизни в других условиях, оказывались более конкурентноспособными по сравнению с предыдущими. Напротив, старшее поколение не могло передать молодежи ни собственность, обладание которой в новых условиях становилось признаком социального успеха, ни привить необходимые новому времени ценностные установки. Скорее, напротив, ценности старшего поколения становились грузом, затрудняющим адаптацию в постсоветских условиях [5, с. 39-54].

Нынешняя группа молодежи (19982004 г. р.) прошла финальную фазу социализации уже после окончания формирования современной российской экономической системы и определяемой ею структуры занятости и трудовой этики. К этому времени уже закончился период неопределенности и связанные с ним ощущения нестабильности и пессимизма, стимулирующие закрепление асоциальных установок [11, с. 65-69]. Период относительной социально-экономической стабильности оставил в прошлом активные прак- тики потребления наркотиков и алкоголя, против табакокурения проводилась государственная политика вытеснения из повседневности [13, c. 18].

Для описания смены ценностной системы молодежи социологами используются различные концепции поколений. Например, В.В. Радаев делит современное российское общество на мобилизационное, поколение оттепели, поколение застоя, реформенное и миллениалов [13, с. 18]. Более распространенной и известной является концепция поколений $\mathrm{X}$, Y и Z. Последней по времени значимой публикацией на эту тему стали результаты исследований, проведенные компанией ValiData по заказу Сбербанка [5]. Согласно результатам этого исследования для поколения Z характерны: смена межпоколенческой конфронтации на отношения комплиментарного сотрудничества, снижение авторитета взрослых, осознаваемое самими взрослыми, рост гиперопеки уже взрослых детей, рост ценностей внутрисемейного общения, ослабление нацеленности на карьеру в противовес намерению работать там, где интересно, причем сам предмет интереса может меняться в зависимости от результата - цель, которую не получается достичь за короткий срок, теряет привлекательность.

Согласно результатам репрезентативного для населения РФ и проведенного в декабpe 2016 г. опроса ВЦИОМ главным отличием нынешней молодежи россияне старше 35 лет считали материальную ориентированность (75\%), общительность (70\%) и расточительность (57\%) [12]. Так российскую молодежь оценивали другие поколения россиян. По данным Фонда «Общественное мнение», в 2008 г. сами молодые россияне на первое место ставили благополучие в семье (75\%) и материальный достаток (62\%), собственное здоровье и хорошую физическую форму (30 \%), а также хорошую, интересную работу (26\%) (данные приведены в [1, с. 134-136]). Как видим, за исключением материальной прагматичности, различные исследования дают существенно различные представления о ценностях современной российской молодежи.

Социологи Фонда социальных исследований в течение нескольких десятилетий изучали процесс адаптации молодежи Самарс- 
кой области к складывающимся социальноэкономическим условиям повседневности. Каждый этап представлял собой опрос 800 жителей региона в возрасте от 14 до 30 лет, репрезентирующий эту возрастную группу по полу, возрасту и типу населенного пункта. Еще в 2001 г. был сформирован специальный инструмент для изучения ценностных ориентаций, включавший в себя как инструментальные характеристики (например, здоровый образ жизни, большой круг общения и др.), так и нормативно-ценностные особенности (стремление получать образование, ориентация на карьеру и пр.) [11]. Данный репертуар самооценок был использован в рамках мониторинга неоднократно, но для нас наибольший интерес представляют изменения, произошедшие в период между 2004 и 2018 годами. За это время возрастная когорта, которая в предыдущих волнах исследования относилась к молодежи, обновилась почти полностью. Можно сказать, что мы сравниваем самооценки различных поколений молодежи Самарской области.

Как видно из таблицы, наиболее явным для молодежи Самарской области (54 \%) является стремление зарабатывать много денег - более половины молодых людей области отмечают эту особенность своей социальной группы. Естественно, это не значит, что все они следуют данной максиме, но это указывает на то, что они учитывают ее в своем повседневном поведении во взаимодействии со своими сверстниками. Вторую строку с большим отрывом занимает стремление получить образование (45 \%), затем молодежь отмечает в себе стремление быть всесторонне развитым (43\%), ориентацию на здоровый образ жизни (41\%) и нацеленность на карьеpy (39 \%). Как видим, первую пятерку черт занимают преимущественно положительные или нейтральные характеристики. Получается, что молодежь сегодня стремится заработать деньги, построить карьеру, получив образование, придерживаясь здорового образа жизни и всесторонне развиваясь.

Самарская молодежь 15-летней давности радикально отличалась от нынешней. В 2004 г. трое из пяти молодых жителей области (60 \%) считали основной (!) чертой своей группы - увлечение спиртными напитками. Вторую-третью строчки тогда делили стремление получать образование и зарабатывать (по 54 \%). Затем следовали равнодушие к окружающим людям (47 \%), большой круг общения (42\%) и нацеленность на карьеру (38 \%). Иначе говоря, из списка наиболее характерных для сегодняшней молодежи черт поведения исчезли увлечение спиртными напитками, равнодушие к окружающим людям

Динамика самооценки молодежи Самарской области (\%, 2004-2018 гг. $N=800)$

\begin{tabular}{|l|c|c|}
\hline \multicolumn{1}{|c|}{ Отличительные особенности поколения } & $\mathbf{2 0 0 4}$ г. & $\mathbf{2 0 1 8}$ г. \\
\hline Стремление зарабатывать много денег & 54 & 54 \\
\hline Стремление получать образование & 54 & 45 \\
\hline $\begin{array}{l}\text { Стремление быть разносторонне развитым (иметь несколько видов образования, } \\
\text { владеть несколькими языками, специальностями) }\end{array}$ & 30 & 43 \\
\hline Ориентация на здоровый образ жизни & 30 & 41 \\
\hline Нацеленность на карьеру & 38 & 39 \\
\hline Большой круг общения & 42 & 32 \\
\hline Желание участвовать в жизни страны, приносить пользу Родине & 13 & 31 \\
\hline Увлечение спиртными напитками & 60 & 27 \\
\hline Желание помогать нуждающимся людям & 10 & 26 \\
\hline Ответственность перед обществом & 13 & 24 \\
\hline Равнодушие к окружающим людям & 47 & 23 \\
\hline Широкий кругозор & 11 & 22 \\
\hline Легкомысленность, беспечное отношение к жизни & 21 & 21 \\
\hline Отсутствие интереса к политике & 20 & 18 \\
\hline Большое количество сексуальных связей & $\mathbf{3 5}$ & 16 \\
\hline Отсутствие интереса к событиям, происходящим в стране, мире & 28 & 15 \\
\hline Использование нечестных методов при достижении целей & 17 & 13 \\
\hline Нежелание работать & 22 & 13 \\
\hline Увлечение наркотиками & $\mathbf{3 1}$ & 9 \\
\hline
\end{tabular}


и большой круг общения. Напротив, актуализировались здоровый образ жизни и тяга к разностороннему развитию. Можно предположить, что нынешняя молодежь видит себя менее подверженной вредным привычкам (в качестве аргумента сюда же можно добавить падение актуальности наркотизма с $35 \%$ до $9 \%$ ).

Очевидно, что обнаруженные тренды носят долговременный характер и те небольшие изменения, которые можно обнаружить уже сегодня, лишь через некоторое время изменят самооценку нынешней молодежи. Тем не менее уже сегодня можно увидеть начавшиеся изменения. Помимо отмеченного выше роста популярности здорового образа жизни и карьерных устремлений, необходимо отметить заметное снижение значимости «получения образования». Несмотря на то что это эта характеристика признается самой молодежью значимой, сама она потеряла в «весе». Если в 2004 г. ееналичие признавали 54 \%, то в 2018 г. только $45 \%$. При этом стремление к карьере практически не изменилось (38 \% и 39 \% соответственно), как и стремление к большим деньгам (54\% и $54 \%$ соответственно). Как видим, при сохранении желания зарабатывать и строить карьеру потребность в образовании распознается самой молодежью значимо меньше, чем 14 лет назад. Можно предположить, что нынешнее поколение молодых самарцев сегодня видит хорошо оплачиваемую работу, карьеру и образование меньше связанными друг с другом, чем предыдущее поколение.

Не вошло в топ-5 самооценок «желание участвовать в жизни страны, приносить пользу Родине» (31 \%), но по сравнению с 2004 г. (13 \%) этот показатель существенно возрос. Иначе говоря, молодые самарцы все чаще видят друг в друге общественно активных людей. На это же указывает рост доли тех, кто отмечает среди сверстников намерение помочь нуждающимся людям (10\% в 2004 г. и $26 \%$ - в 2018 г.), чувство ответственности перед обществом (13\% и $24 \%$ соответственно), а также сокращение доли фиксирующих отсутствие интереса к общественным событиям, происходящим в стране и мире в целом (28\% и $15 \%$ соответственно).

Однако неверно понимать такую динамику как рост самооценки политической ак- тивности молодежи. Скорее, речь идет о деятельности, не связанной с политикой. Отсутствие политической активности отмечали респонденты в 2004 г. (20 \%), и эта оценка значительно не изменилась в 2018 г. (18\%).

Важным представляется существенное сокращение количества тех, кто зафиксировали «большое число сексуальных контактов» в молодежной среде с $35 \%$ в 2004 г. до $10 \%$ в 2018 году. Иначе говоря, сегодня молодежь считает, что ведет более размеренную сексуальную жизнь, что в целом подтверждается увеличением возраста первых рождений у женщин, возраста вступления в первый брак, сокращением числа абортов и прямых данных о числе сексуальных контактов.

Таким образом, ценностные ориентации молодых людей приобрели качественно новые черты, не свойственные прежней молодежи и поведению представителей старших возрастных групп. Во-первых, нынешняя молодежь отмечает в себе ориентацию на трудовую деятельность, карьерные достижения и финансовый успех. Во-вторых, наблюдается радикальное ослабление девиантных практик - злоупотребления алкоголем, наркотиками, и, напротив, происходит расширение практик здорового образа жизни. В-третьих, можно отметить расширение практик добровольного участия в помощи другим людям, но по-прежнему - неучастие в политической жизни. В-четвертых, происходит ослабление стремления к получению образования как инструмента для жизненного или трудового успеха.

\section{СПИСОК ЛИТЕРАТУРЫ}

1. Звоновский, В. Б. Социология пространства повседневности / В. Б. Звоновский. - Самара : Самарский ун-т. $-2009 .-168$ с.

2. Зоркая, Н. А. Ценности и установки российской молодежи / Н. А. Зоркая, Н. М. Дюк // Мониторинг общественного мнения: экономические и социальные перемены. - 2003. - № 4 (66). - С. 66-77.

3. Ибрагимова, Д. Х. Когортный анализ потребительских ожиданий населения России (19962010): теоретико-методологические основы исследования / Д. Х. Ибрагимова // Экономическая социология. - 2014. - Т. 15, № 2. - С. 99-118.

4. Иванова, Е. И. Проблема поколений и воспроизводство населения: теоретические подходы и 
реальность / Е. И. Иванова // Социологические исследования. - 2012. - № 4. - С. 42-53.

5. Исследование Сбербанка: 30 фактов о современной молодежи. - Электрон. текстовые дан. Режим доступа: https:/adindex.ru/news/researches/2017/ 03/10/158487.phtml (дата обращения: 24 10.2018). -Загл. с экрана.

6. Кесельман, Л. Е. Индивидуальный экономический оптимизм/пессимизм в трансформирующемся обществе / Л. Е. Кесельман, М. Г. Мацкевич // Социологический журнал. - 1998. - № 1-2. - С. 39-54.

7. Козлова, Т. З. Оценка старшим поколением молодежи / Т. 3. Козлова. - Электрон. текстовые дан. - Режим доступа: http://anthropology.ru/ru/texts/ kozlova_tz/gerontos_38.html (дата обращения: 24.10.2018). - Загл. с экрана.

8. Косова, Л. Б. Третий возраст: социальное самочувствие / Л. Б. Косова // Демоскоп Weekly. 2015. - № 667-668. - С. 1-12.

9. Лисовский, В. Т. Ценности жизни и культуры молодежи (социологическое исследование) / В. Т. Лисовский. - Электрон. текстовые дан. Режим доступа: http://anthropology.ru/ru/texts/ lisovsky/mys101_09.html (дата обращения: 24.10. 2018). - Загл. с экрана.

10. Магун, В. С. Динамика притязаний и изменение ресурсных стратегий молодежи: 1985-2005 годы / В. С. Магун, М. В. Энговатов // Отечественные записки. - 2006. - № 3. - С. 76-96.

11. Молодежь Самарской области в 2003 году: современное положение и тенденции развития. Научно-информационный бюллетень / под ред. В. Б. Звоновского. - Самара : Фонд социальных исследований. $-2004 .-222$ с.

12. Поколение Selfie: пять мифов о современной молодежи. - Электрон. текстовые дан. - Режим доступа: https://wciom.ru/index.php?id=236\&uid=115996 (дата обращения: 24.10.2018). - Загл. с экрана.

13. Радаев, В. В. Миллениалы на фонепредшествующих поколений: эмпирический анализ / В. В. Радаев // Социологические исследования. - 2018. - № 3.C. 15-33.

\section{REFERENCES}

1. Zvonovskiy V. B. Sotsiologiya prostranstva povsednevnosti [Sociology of Everyday Life Space]. Samara, Samarskiy un-t Publ., 2009. 168 p.

2. Zorkaya N.A., Dyuk N.M. Tsennosti i ustanovki rossiyskoy molodezhi [Values and Attitudes of Russian Youth]. Monitoring obshchestvennogo mneniya: ekonomicheskie $i$ sotsialnye peremeny, 2003, no. 4 (66), pp. 66-77.

3. Ibragimova D.Kh. Kogortnyy analiz potrebitelskikh ozhidaniy naseleniya Rossii (1996-
2010): teoretiko-metodologicheskie osnovy issledovaniya [Cohort Analysis of Consumer Expectations of Russian Population (1996-2010): Theoretical and Methodological Foundations of the Research]. Ekonomicheskaya sotsiologiya, 2014, vol. 15, no. 2, pp. 99-118.

4. Ivanova E.I. Problema pokoleniy i vosproizvodstvo naseleniya: teoreticheskie podkhody i realnost [The Problem of Generations and Population Reproduction: Theoretical Approaches and Reality]. Sotsiologicheskie issledovaniya, 2012, no. 4, pp. 42-53.

5. Issledovanie Sberbanka: 30 faktov o sovremennoy molodezhi [Sberbank's Research: 30 Facts about Today's Youth]. URL: https://adindex.ru/ news/researches/2017/03/10/158487.phtml (accessed 24 October 2018)

6. Keselman L.E., Mackevich M.G. Individualnyy ekonomicheskiy optimizm/pessimizm v transformiruyushchemsya obshchestve [Individual Economic Optimism / Pessimism in Transforming Society]. Sotsiologicheskiy zhurnal, 1998, no. 1-2, pp. 39-54.

7. Kozlova T.Z. Otsenka starshim pokoleniem molodezhi [The Older Generation's Evaluation of Youth]. URL: http://anthropology.ru/ru/texts/kozlova_ tz/gerontos_38.html. (accessed 24 October 2018)

8. Kosova L.B. Tretiy vozrast: sotsialnoe samochuvstvie [the Third Age: Social Well-Being]. Demoskop Weekly, 2015, no. 667-668, pp. 1-12.

9. Lisovskiy V.T. Tsennosti zhizni i kultury molodezhi (sotsiologicheskoe issledovanie) [Values of Life and Culture of Youth (Sociological Research)]. URL: http://anthropology.ru/ru/texts/lisovsky/ mys101_09.html (accessed 24 October 2018)

10. Magun V.S., Engovatov M.V. Dinamika prityazaniy i izmenenie resursnykh strategiy molodezhi: 1985-2005 gody [The Dynamics of the Claims and the Change of Resource Strategies of Youth: 1985-2005]. Otechestvennye zapiski, 2006, no. 3, pp. 76-96.

11. Zvonovskiy V.B., ed. Molodezh Samarskoy oblasti v 2003 godu: sovremennoe polozhenie $i$ tendentsii razvitiya. Nauchno-informatsionnyy byulleten [Youth of the Samara Region in 2003: Current Situation and Development Trends. Scientific and Information Bulletin]. Samara, Fond sotsialnykh issledovaniy Publ., 2004. 222 p.

12. Pokolenie Selfie: pyat mifov o sovremennoy molodezhi [Selfie Generation: Five Myths about the Modern Youth.] URL: https://wciom.ru/index. php?id=236\&uid=115996 (accessed 24 October 2018)

13. Radaev V.V. Millenialy na fone predshestvuyushchikh pokoleniy: empiricheskiy analiz [Millennials against the Background of Previous Generations: Empirical Analysis]. Sotsiologicheskie issledovaniya, 2018, no. 3, pp. 15-33. 


\section{СОЦИОЛОГИЯ И СОЦИАЛЬНЫЕ ТЕХНОЛОГИИ}

\section{Information about the Author}

Vladimir B. Zvonovsky, Doctor of Sciences (Sociology), Head of Departament of Sociology and Psychology, Samara State University of Economics, Soviet Army St., 141, 443090 Samara, Russian Federation, zvb@socio-fond.com.

\section{Информация об авторе}

Владимир Борисович Звоновский, доктор социологических наук, заведующий кафедрой социологии и психологии, Самарский государственный экономический университет, ул. Советской Армии, 141, 443090 Самара, Российская Федерация, zvb@socio-fond.com. 